EM

\title{
UMA CIDADE, UM CENÁRIO DO AGRONEGÓCIO E SUAS EMPRESAS HOTELEIRAS
}

\section{A CITY, AN AGRIBUSINESS SCENARIO AND ITS HOTEL COMPANIES}

\author{
Jean Carlos Vieira SANTOS ${ }^{1}$ \\ Kelem Ferreira CARDOSO ${ }^{2}$
}

\begin{abstract}
Resumo: Este texto visa analisar e apresentar a realidade hoteleira do espaço urbano de Quirinópolis, Goiás. As atividades são realizadas em uma cidade que não é turística, mas sustentada pelos capitais investidos no agronegócio. Para a construção desse trabalho, foram fundamentais o levantamento de referencial teórico, os trabalhos de campo, a aplicação de questionários, as entrevistas informais e o trabalho de gabinete. Entre os principais resultados apresentados pela pesquisa, apenas $22,22 \%$ dos inquiridos têm curso superior; é oferecido o café da manhã em $88,89 \%$ dos estabelecimentos investigados; 77,78\% das Unidades Habitacionais (UHs) possuem telefones; e para 88,89\% dos sujeitos pesquisados, as empresas do agronegócio são as grandes responsáveis pela ocupação dos leitos hoteleiros.
\end{abstract}

Palavras-Chave: Quirinópolis; Hotelaria; Espaço urbano; Agronegócio.

Abstract: This text intends to analyze and present the hotelier reality in the urban space of Quirinópolis, Goiás. The activities are developed in a city that is not touristic, but it is supported by the capital invested in agribusiness. For the construction of this work, the theoretical framework survey, the fieldwork, the application of questionnaires, the informal interviews and the cabinet work were essential. Among the main results presented by the research, only $22.22 \%$ of the respondents have a college degree; $88.89 \%$ of the investigated establishments offer breakfast; $77.78 \%$ of the Housing Units (HUs) have telephones; and for $88.89 \%$ of the surveyed subjects, the agribusiness companies are largely responsible for the occupation of hotel beds.

Keywords: Quirinópolis; Hotel business; Urban space; Agribusiness.

\section{Introdução}

Este texto visa analisar e apresentar a realidade hoteleira do espaço urbano de Quirinópolis, Goiás ${ }^{3}$. As atividades são desenvolvidas em uma cidade que não é turística, mas sustentada pelos capitais investidos no agronegócio, com duas grandes usinas que produzem álcool e açúcar, uma cooperativa, propriedades rurais destinadas ao confinamento de gados e outras ações ligadas à agropecuária.

Nessa cidade pequena do interior goiano, a hotelaria se tornou um segmento capaz de gerar renda e emprego, além de ampliar e diversificar os negócios do lugar. De acordo com Souza (2015), o município de Quirinópolis está localizado na Mesorregião do Sul Goiano e

\footnotetext{
${ }^{1}$ Docente dos Mestrados Territórios e Expressões Culturais no Cerrado (TECCER/UEG/Anápolis) e Geografia (PPGEO/UEG/Cora Coralina, e dos cursos de Graduação e Tecnologia da UEG Caldas Novas (GO). Pósdoutorado em Turismo pela Universidade do Algarve/Portugal e Doutorado em Geografia pela Universidade Federal de Uberlândia (MG). E-mail: svcjean@yahoo.com.br

${ }^{2}$ Graduada em Geografia pela Universidade Estadual de Goiás - Campus Sudoeste (Quirinópolis/Goiás). Foi Bolsista Permanência no Curso de Geografia (UEG). E-mail: kelemfcquiri@gmail.com

${ }^{3}$ Este trabalho é resultado do projeto de pesquisa: "Turismo e Estratégias Territoriais no Cerrado: destinos e cidades em Goiás”, desenvolvido na Universidade Estadual de Goiás - UEG.
} 
EM

tem a posição geográfica determinada pelas coordenadas $18^{\circ} 26^{\prime}$ '52" (latitude Sul) e $50^{\circ} 27^{\prime}$ 07" (longitude Oeste), com área territorial de 3.780,695 km² (Figura 1). Vale ressaltar que a população é de aproximadamente 50 mil habitantes.

Figura 1 - Localização do município de Quirinópolis/GO.

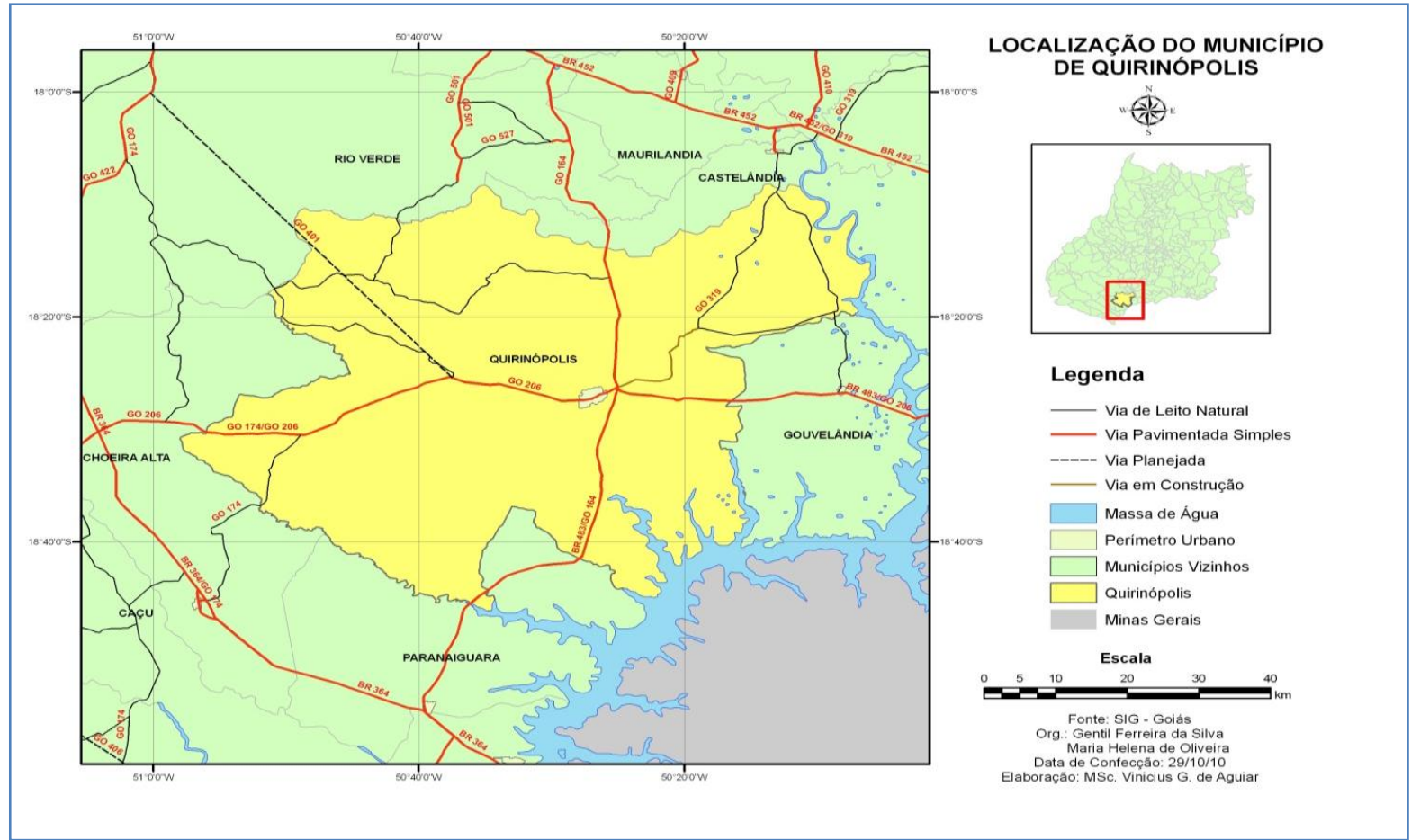

Fonte: Costa e Silva (2015).

"Nas últimas décadas, ao receber investimentos econômicos de empreendimentos do agronegócio, o município tem se desenvolvido como um polo importante na produção de biocombustível, sobretudo o etanol, subsidiando duas usinas sucroalcooleiras de grande porte" (ALVES; SILVA, 2017, p. 203). Tal município está em uma área estrategicamente escolhida pelo capital agrário:

[...] pelo seu forte potencial de elementos naturais, de organização e coordenação do processo produtivo, acolhendo duas agroindústrias da canade-açúcar para a fabricação de etanol e/ou açúcar, e também outras empresas de produção e serviços ligadas a este setor (SOUZA, 2015, p. 7).

Vale sublinhar que, nas primeiras décadas do século XXI, a hotelaria em Quirinópolis ganhou enorme impulso, com a instalação de usinas produtoras de açúcar e álcool no município. Há uma crescente demanda e transformação dessa atividade no espaço urbano, pois antigos e novos proprietários de hotéis buscaram criar condições e infraestruturas necessárias para a cidade receber os novos sujeitos ligados as empresas do agronegócio.

Nesse contexto, o advento do agronegócio e a modernização da economia nas regiões do Cerrado brasileiro provocaram alterações de diversas ordens no setor de serviços. No caso deste artigo será destacado o segmento hoteleiro, que se tornou um componente do desenvolvimento da agricultura e pecuária em cidades pequenas, a exemplo de Quirinópolis.

Assim, "essa proposta se constituiu em uma pesquisa de ordem exploratório/descritiva, de cunho qualitativo e quantitativo [...]" (SOUZA; THOMAZ, 2014, p. 154). Os procedimentos metodológicos utilizados na construção deste artigo foram: a) revisão 
EM

bibliográfica acerca de uma análise histórica da hotelaria na Europa, América Anglo-Saxônica e no Brasil, além das implicações nos âmbitos globais e territoriais; b) a coleta de dados no campo, fazendo o uso de levantamento inicial de informação in loco e posteriormente elaboração e aplicação de questionários.

\section{Hotéis e Hotelaria na Europa e América Anglo-Saxônica: uma breve análise teórica}

Discussões científicas sobre a hotelaria em espaços urbanos e cidades pequenas do interior brasileiro são recentes, assentadas basicamente em algumas escolas e investigações acerca da geografia, economia, antropologia e da ciência do turismo. Mesmo diante de uma evolução no tempo e espaço, lacunas são encontradas, sobretudo em municípios que não são definidos como turísticos, a exemplo de Quirinópolis.

Antes de analisar e compreender o recorte de estudo proposto neste artigo é necessário apresentar a evolução histórica da hotelaria na Europa, América Anglo-Saxônica e no Brasil, trazendo uma produção científica e epistemológica com análises de cunho teórico. Inicialmente, para Walker (2002), a origem e a evolução da hotelaria estão vinculadas a grandes marcos históricos.

$\mathrm{O}$ incremento do comércio e, consequentemente, das viagens, fez surgir algumas formas de acomodação para se passar a noite, tornando-a uma necessidade absoluta. $\mathrm{Na}$ Antiguidade, as rotas comerciais entre a Europa e o Oriente geravam movimento nas cidades, levou à criação de centros de hospedagem para o acolhimento dos viajantes.

À época, os hóspedes se instalavam em quartos ou outras partes das residências oferecidas pela população de cidades comerciais (WALKER, 2002; FERREIRA; FARANI; SANTOS, 2008). De acordo com Amazonas (2006), havia no Império Romano um conceito superior de hospedarias chamado de hostellum, que abrigava as pessoas de classes mais abastadas, como os nobres e reis. Com o aumento das viagens, comerciantes, atores e estudiosos passaram a se hospedar em tavernas e estalagens.

Walker (2002) assevera que, na Idade Média, mosteiros e abadias passaram a hospedar os viajantes. Com o surgimento das carruagens, o número de viagens aumentou e, consequentemente, a quantidade de estabelecimentos de hospedagem cresceu às margens das estradas na Europa. Ademais, elevou-se a qualidade de tais estabelecimentos, uma vez que, diversos viajantes eram abastados e possuíam mais exigências em relação à qualidade dos serviços oferecidos.

Posteriormente, de acordo com Andrade, Brito e Jorge (2003), com o surgimento das monarquias nacionais, o Estado se tornou responsável pelo acolhimento dos viajantes. Assim, palácios da nobreza, instalações militares e administrativas passaram a ser utilizados para a recepção dos hóspedes. As pessoas que não eram beneficiadas com tais meios de hospedagem eram recepcionadas em albergues e estalagens. Naquela época, na França, foram criadas as primeiras leis que regulamentavam tanto a segurança quanto as tarifas nas hospedarias.

Com base em Rodrigues (2006), Ferreira, Farani e Santos (2008), salienta-se que, com a Revolução Industrial e a expansão do capitalismo, a hospedagem ganhou novas características e passou a ser um forte ingrediente da economia mundial. Na Inglaterra, por exemplo, entre 1750 e 1820, as estalagens foram substituídas pelos inns, que ofereciam serviços diversos, excelente alimentação e alto padrão de limpeza, visando atender às exigências cada vez maiores dos hóspedes que agora, eram consumidores. Com o avanço em ferrovias e estradas de rodagem que ligavam as cidades portuárias aos grandes centros, houve a necessidade de estabelecimentos como o Hotel de Henrique IV, que em 1788 foi construído na cidade de Nantes, França, e é considerado um dos primeiros hotéis europeus. 
EM

Ainda segundo Andrade, Brito e Jorge (2003), em 1870, o suíço César Ritz construiu o primeiro hotel em Paris, que possuía quartos com banheiros privativos (hoje chamados de apartamentos) e funcionários uniformizados, o que deu início à chamada "hotelaria planejada". Conforme Rodrigues (2006), em 1794 foi inaugurado, com 73 quartos, o primeiro hotel nos Estados Unidos, chamado de City Hotel, na Broadway, em Nova Iorque.

Em seguida surgiram outros estabelecimentos desse tipo, com destaque para o Tremont House em Boston (EUA), o qual introduziu na hotelaria os mensageiros, recepcionistas e o conceito de apartamentos double (acomodação para duas pessoas) e single (acomodação para um indivíduo). Os hotéis passaram a oferecer serviços diferenciados como os elevadores, os quais foram introduzidos primeiramente em 1859, no Fifth Avenue Hotel de Nova Iorque. Diante desse contexto histórico, pontua-se que:

O ensino na área de turismo nasceu na Suíça com a fundação, em 1893, da primeira escola hoteleira em Aochy, mas, verdadeiramente, só começou a ser organizado a partir de 1914, quando na Itália, o ENIT - Ente Nazionale per L'Industrie Turistiche -, inscreveu, entre os seus objetivos, a preparação do pessoal da hotelaria. $\mathrm{Na}$ altura as profissões turísticas eram reduzidas e poucos iam além da hotelaria e das que eram exercidas nas poucas agências de viagens existentes, pelo que a formação turística se limitava à preparação dos empregados destinados aos hotéis (CUNHA, 2012, p. 189).

Conforme Andrade, Brito e Jorge (2003), em 1908, o conceito de hotelaria planejada atingiu os Estados Unidos, e a inauguração do Statler Hotel marcou a modernização do setor. $\mathrm{O}$ acelerado crescimento da hotelaria no referido país se deve ao fato de que os hotéis foram abertos para ser desfrutados por qualquer pessoa da comunidade, ao contrário da Europa, onde somente a aristocracia poderia usufruir dos serviços.

Outro marco importante na história da hotelaria foi a Segunda Guerra Mundial. Ela impulsionou a economia e trouxe avanços para o transporte (aviões a jato para passageiros) e comunicação, o que facilitou a locomoção de pessoas e mercadorias. Com a recuperação dos países após a guerra e a expansão da economia, o turismo se tornou uma importante atividade econômica, os indivíduos passaram a ter uma renda maior, que poderia ser aplicada em viagens e passeios turísticos, promovendo o crescimento das redes hoteleiras (ANDRADE; BRITO; JORGE, 2003).

Nesse período definido por Cunha (2012, p. 65) como turismo moderno:

A evolução das viagens que deram origem ao turismo moderno, desde o seu início no século XVII até finais do século passado (XX), podem caracterizarse, quanto à orientação geográfica dos fluxos turísticos, por dois grandes tipos de movimentos organizados em função das motivações dominantes dos viajores: um marcadamente individualista e itinerante, e outro constituído por famílias e/ou pequenos grupos que se dirigiam para locais precisos para aí desfrutarem de benefícios que os locais de residência ofereciam.

Em 1950, Haward Dearing Johnson inaugurou o primeiro meio de hospedagem, um motel situado em Savannah, Geórgia (EUA), cujo atendimento era voltado preferencialmente a motoristas e famílias de autoeestradas. "Conforme as viagens de negócios foram se intensificando, áreas de lazer, salas de reuniões e salões de jantar foram sendo incorporados" (WALKER, 2002, p. 25). Por sua vez, a capital de Portugal, Lisboa, recebeu em 1958 uma pequena instituição de ensino "designada Escola Alexandre de Almeida, nome do pioneiro da hotelaria portuguesa e da formação profissional, mas com uma capacidade formativa muito 
EM

reduzida e instalada num edifício em condições inapropriadas para os seus fins" (CUNHA, 2012, p. 189).

Em 1960, foi a vez de Isadore Sharp fundar o grupo Four Seasons Regent Hotels, que nasceu como um motel em Jarvis Street, Toronto, Canadá. "O grupo é hoje a maior cadeia de hotéis de luxo no mundo, um império global de muitos milhões de dólares" (WALKER, 2002, p. 26). Atualmente, há dezenas de estabelecimentos dessa rede espalhados por todo o mundo, além de outros que estão em fase de planejamento.

Na região de Algarve, em Portugal, um dos principais destinos turísticos em nível mundial, o primeiro hotel (Vasco da Gama, em Monte Gordo) foi aberto em 1960 e, nos primeiros anos da década, o turismo algarvio tinha características de passagem, apoiado em menos de meia dúzia de unidades hoteleiras. Porém, a partir daquele ano, as acomodações de estrangeiros cresceram mais rapidamente do que no resto do país, multiplicando-se por quatro até 1963, ao passo que, no resto de Portugal, aumentaram 1,5 vezes (CUNHA, 2012; SANTOS; SILVA, 2015).

Diante dos fatos citados, comprova-se que a globalização e a sedimentação do capitalismo incrementaram a atividade do turismo, tornando-o um fator intrínseco à hotelaria mundial. Rodrigues (2006) explica que a tendência mundial mediante as exigências dos consumidores é a especialização da mão de obra e dos padrões de hospedagem.

Nessa vertente, pondera-se que os hotéis se caracterizam por um número específico de quartos ou apartamentos. Os serviços de quarto são executados diariamente, como a preparação das camas e a limpeza - eles são agrupados em classes ou categorias (CUNHA, 2001). O conceito de hotéis econômicos (hard budget) nasceu:

[...] em 1985 nos EUA, mas rapidamente se estendeu à Europa, em especial a França, baseado nos conceitos de conforto, calma e limpeza. São os designados supermercados de dormir, caracterizados por métodos de construção modernos, especialmente pela utilização de materiais préfabricados, quartos de pequena dimensão (normalmente nove metros quadrados), máxima tecnologia, mínimo de empregados, sem restaurante e localização junto das estradas de acesso às grandes cidades. O seu objetivo é oferecer uma dormida por pouco dinheiro (CUNHA, 2001, p. 205).

Variados serviços são oferecidos pelos hotéis contemporâneos. Eles podem ser tecnológicos - telefone, minibar, tomada para computador, antena de satélite, internet, fax, acesso à multimídia; modernos - “[...] secretariado, centro de negócios, salas de reuniões e de seminários, serviços para automóveis. Serviços de lazer: além das tradicionais piscinas, têmse campo de tênis, jogos, sauna, sala de ginástica, clube de criança etc." (CUNHA, 2001, p. 208-209).

Com o processo evolutivo, as cadeias hoteleiras foram normalmente criadas por instituições "[...] financeiras, companhias aéreas ou operadores turísticos com o fim de diversificarem os seus investimentos financeiros e as atividades econômicas da empresa ou proceder a uma integração vertical ou horizontal dos seus negócios" (CUNHA, 2001, p. 241). Entre os exemplos se destacam estas redes: Accor - sociedade francesa com milhares de hotéis (Novotel, Mercure, Ibis, Formule 1, entre outros); Bass Hotel \& Resorts - cadeia inglesa (Holiday-in, Plaza etc.); Starwood - cadeia norte-americana (Sheraton, Westin etc.).

Em consonância ao processo de modernização:

[...] a internet constitui uma fonte de informação e de conhecimento à escala mundial que permite a todos os utilizadores, sem necessidade de intermediários, de aceder às informações. A proliferação da rede e a sua 
EM

aceitação universal pressupõe a utilização de novas práticas de funcionamento a fim de melhorar a competitividade [...] turística (CUNHA, 2001, p. 319).

Surgiram diferentes tipos de hotéis com características decorrentes da localização e do segmento de mercado em que estão inseridos. À medida que o acesso à informação se tornou cada vez mais fácil, rápido e abrangente, a maneira de agir e de pensar do indivíduo sofreu mudanças significativas e de forma gradual. A sociedade de consumo passou a se interessar pela busca de culturas e lugares desconhecidos.

\section{Hotelaria no Brasil: uma trajetória histórica}

No Brasil, a hotelaria nasce por volta do século XVI, juntamente com a colonização portuguesa. À época, os hóspedes eram recebidos nas casas-grandes de engenhos e fazendas, nos conventos, nos casarões das cidades e em pousadas e ranchos que existiam à beira das estradas. A localização desses últimos propiciou, próximo a eles, o surgimento de outras atividades comerciais, o que deu origem a aglomerados populacionais e, por vezes, a cidades - vale ressaltar que havia também os quartos de hóspedes nas casas de famílias. Já no século XVIII, no Rio de Janeiro, começaram as "casas de pasto", alojamentos para os viajantes que dariam origem aos futuros hotéis (ANDRADE; BRITO; JORGE, 2003; FERREIRA; FARANI; SANTOS, 2008).

Em 1808, com a chegada da corte portuguesa no Rio de Janeiro, foi necessário aumentar a infraestrutura na colônia, por ter chegado um grande número de estrangeiros que precisavam de alojamentos. "Os proprietários da maioria das casas de pensão, hospedarias e tavernas passaram a utilizar a denominação de hotel, com a intenção de elevar o conceito de casa" (ANDRADE; BRITO; JORGE, 2003, p. 21).

Nesse contexto se destaca o Hotel Pharoux, um dos estabelecimentos de maior prestígio à época, por ser de classe internacional. Entretanto, ainda era escassa a quantidade desse tipo de empresa, problema que prosseguiu até o século XX. Tal situação levou o governo, em 1907, a criar o Decreto n. 1.160, o qual desobrigava os cinco primeiros grandes hotéis que se instalassem no Rio de Janeiro a efetuar o pagamento de impostos municipais durante sete anos. Esse dispositivo impulsionou a construção de hotéis na cidade, como Hotel Avenida (1908), Hotel Glória (1922) e Copacabana Palace (1923) - o último foi o marco da hotelaria na cidade do Rio de Janeiro, consolidando-a como um polo de turismo e lazer (ANDRADE; BRITO; JORGE, 2003).

De acordo com Amazonas (2006), o início das atividades de hospedagem na cidade de São Paulo ocorreu no século XVII. Elas eram exercidas por barbeiros, alfaiates, sapateiros e profissionais de outros setores que possuíam estalagens e se referiam a vendedores de alimentos e hospedagem. Com o advento do turismo de negócios, o setor começou a ganhar destaque internacional.

Nas décadas de 1930 e 1940, segundo Amazonas (2006), foram construídos grandes hotéis nas capitais e estâncias minerais, devido aos incentivos do governo. Destaca-se o Grande Hotel São Pedro, na cidade de Águas de São Pedro, que hoje abriga a maior escola de hotelaria da América Latina, administrada pelo Serviço Nacional de Aprendizagem Comercial (SENAC). Vale lembrar que, em 1946, os jogos de azar foram proibidos, e os cassinos, fechados; logo, os hotéis associados às jogatinas também encerraram suas atividades. Ferreira, Farani e Santos (2008) discorrem que o Grande Hotel foi o primeiro empreendimento hoteleiro da cidade de Goiânia e uma das mais importantes construções na época, sendo inaugurado em 23 de janeiro de 1937, no atual setor central. 
EM

Cumpre dizer que, para Andrade, Brito e Jorge (2003), em 1966 foram criados o Instituto Brasileiro de Turismo (EMBRATUR) e o Fundo Geral de Turismo (FUNGETUR), que fomentaram a construção de hotéis de luxo por meio de incentivos fiscais (SUDENE, SUDAM) e financiamentos de longo prazo (EMBRATUR, FINAME).

Nos anos 1960 e 1970 chegaram também ao Brasil as redes hoteleiras internacionais; por conseguinte, houve uma grande expansão dos hotéis tanto nacionais quanto estrangeiros, a exemplo das redes Othon e Luxor. Entretanto, esse crescimento não ocorreu de forma equilibrada, havendo um número muito maior de hotéis de cinco estrelas do que de estabelecimentos de categoria média e econômica. Isso ocasionou uma demanda mal servida, composta por viajantes e comerciantes ligados ao mundo dos negócios e serviços, pois eles procuravam por hotéis com tarifas mais acessíveis, e não as praticadas pelas empresas de cinco estrelas.

Amazonas (2006) pondera que, em função da crise econômica do início da década de 1980, com a paralisação (quase) total da indústria imobiliária de locação residencial, do pequeno número de hotéis com preços acessíveis, do fim de financiamentos em longo prazo e de incentivos fiscais, houve um surto na construção dos apart-hotéis (flat services), uma alternativa criada pelo mercado imobiliário a fim de incrementar a hotelaria nacional. Esse tipo de hospedagem, além de possuir baixo custo, é barato para o hóspede e possui qualidade em relação aos serviços hoteleiros. Tal novidade, ao atender a mudanças econômicas e sociais, favorecia tanto os usuários quanto os empreendedores. São Paulo foi a cidade pioneira desse serviço, caracterizada por ser um importante centro de negócios.

Já na década de 1990, início do governo Collor, o Banco Nacional de Desenvolvimento Econômico e Social (BNDES) passou a oferecer linhas de crédito especiais para a implantação de hotéis. Isso evidencia uma nova fase de desenvolvimento da indústria hoteleira ao dar continuidade à tendência anterior, visto que mais hotéis luxuosos estavam sendo construídos (AMAZONAS, 2006).

Ainda de acordo com Amazonas (2006), em 1994, com a implantação do Plano Real, os benefícios para a hotelaria foram ainda maiores. A estabilidade econômica atraiu investidores nacionais e estrangeiros e, assim, vários hotéis foram construídos, principalmente nas grandes cidades - nessa época houve uma das maiores expansões da indústria hoteleira. Também foi nesse período que as cadeias hoteleiras internacionais aumentaram os investimentos no mercado brasileiro, principalmente em hotéis econômicos, acirrando a concorrência nacional. Desse modo, os preços se tornaram mais competitivos e os padrões de qualidade foram aprimorados.

De fato, a década de 1990 foi um dos períodos de maior expansão da oferta da indústria hoteleira (AMAZONAS, 2006), com a inauguração de vários hotéis de luxo em todo o país: Belo Horizonte (Ouro Minas), São Paulo (Meliá, Inter-Continental, Renaissance e Sofitel), Porto Alegre (Sheraton), Pernambuco (Blue Tree Cabo de Santo Agostinho e Summer Ville), Costa de Sauípe, na Bahia (cinco hotéis de luxo), além de grandes reformas nos estabelecimentos da cidade de Rio de Janeiro. Já em relação aos apart-hotéis, o mercado caminhou para uma superoferta em Belo Horizonte e São Paulo, uma vez que não havia demanda por mais unidades nesse segmento de mercado.

A partir década de 1990, observa-se uma nova organização do setor hoteleiro, relacionada ao processo de globalização, o que aumentou a concorrência, internacionalizou as empresas e reconfigurou as sociedades. A maneira de conduzir um negócio hoteleiro mudou completamente, posto que a administração passou a ser estritamente profissional, e as especializações de mão de obra se tornaram cada vez mais necessárias e obrigatórias.

Os nichos explorados se tornaram bem distintos: de um lado, a categoria luxo, que continua em expansão e possui muitos adeptos; e, do outro, as hotelarias econômica e 
EM

supereconômica, que surgiu como alternativa aos luxuosos, mas que também desfrutam de qualidade no atendimento e nos serviços prestados, além do conforto. "Um hotel econômico ou supereconômico oferece quartos limpos, mobiliados e razoavelmente espaçosos sem os detalhes supérfluos dos hotéis de serviço completo" (WALKER, 2002, p. 103). Ainda de acordo com o autor, com exceção do café da manhã, o serviço de alimentos e bebidas geralmente não é disponibilizado aos hóspedes.

É notável que o Brasil possui grande número unidades na categoria econômica, em que a maioria pertence à rede francesa Accor, por meio das marcas Ibis e Formule 1. Com base nas obras estudadas, pode-se afirmar que a hotelaria global, nacional, regional e local se desenvolve a partir do momento em que "[...] os turistas passaram ser mais exigentes, a qualidade transformou-se em fator de decisão das viagens e adquiriram maior capacidade de seleção dos destinos" (CUNHA, 2012, p. 404).

Nessa perspectiva, um dos acontecimentos mais marcantes é o desenvolvimento de novas Tecnologias de Informação e Comunicação (TICs) e sua associação com os sistemas globais de divulgação dos serviços hoteleiros nas páginas disponibilizadas na rede mundial de computadores. A seguir será apresentada a realidade da cidade de Quirinópolis, com os hotéis de gestão familiar situados nas proximidades do terminal rodoviário e nas principais avenidas do centro urbano. Em alguns casos, são utilizados simultaneamente como residência própria e podem ser caracterizados como pequenas empresas.

\section{Quirinópolis e os negócios hoteleiros: um contexto gerador de renda e emprego}

Os primeiros meios de hospedagens da cidade de Quirinópolis surgiram por iniciativa de moradores que não tinham nenhuma experiência com hotelaria, mas que buscaram nessa atividade uma forma de sobrevivência e renda. Isso levou ao surgimento dos primeiros leitos de hospedagem urbanos nas primeiras décadas do século $\mathrm{XX}$, principalmente nas proximidades dos terminais rodoviários.

Nesse entremeio, a primeira rodoviária se localizava na Avenida Garibaldi Teixeira, esquina com a Rua Herculano Costa (atual Clínica Sagrado Coração, no Centro). Já em 2019, o terminal rodoviário se encontra entre as Avenidas Brasil e Rui Barbosa, setor central da cidade. De acordo com os depoimentos informais obtidos durante os trabalhos de campo, é possível destacar as primeiras pensões do município, entre elas as da Dona Crioula e Guanabara, que existiam onde se localiza, em 2019:

[...] o HSBC, onde é aquela loja ali naquele espaço entre o HSBC e aquela loja de móveis Novo Mundo. Então, naquele espaço ali tinha a Pensão da Dona Crioula. A Pensão Guanabara ficava onde foi, durante muito tempo, a Tipografia Esmeralda, em frente à CEQ - ela era a melhor pensão de Quirinópolis. Fiquei muito lá quando menina. Na Dona Crioula, quando nós viemos de Minas pra Goiás, era lá quase em frente à Caixa Econômica essa pensão (DEPOIMENTO INFORMAL OBTIDO EM PESQUISA DE CAMPO, 2016-2018).

A Pensão da Dona Crioula ficava a duas quadras do primeiro terminal rodoviário. A inquirida destaca também as transformações ocorridas ao longo dos últimos anos no espaço urbano de Quirinópolis, sobretudo nos meios de hospedagens. Nesse momento surgem também novos conceitos e estruturas, pois continuam as atividades em residências (pensões); entretanto, surge uma nova lógica de serviços de hospedagens denominada hotel, ou seja, uma empresa: 
EM

[...] de prestação de serviços e diferencia-se completamente de outros estabelecimentos industriais e comerciais. [...] O produto hoteleiro é estático, pois o consumidor deve ir até ele, já as empresas industriais ou comerciais fazem o produto chegar até o cliente. A empresa hoteleira, quando comparada a outros tipos de empresa, é menos propensa à automação, pois o tratamento pessoal, o calor humano faz parte essencial da prestação dos serviços hoteleiros (BENI, 2003, p. 30).

Para a entrevistada, o nome "hotel" foi uma novidade para a realidade encontrada nesse espaço urbano do interior de Goiás:

[...] hotel aqui em Quirinópolis foi o primeiro, eu não tenho certeza, mas o Hotel dos Viajantes. Em frente ao Hospital São Francisco tinha uma pensão, meu marido ficou lá. [...] os primeiros hotéis que eu lembro aqui foi [sic] o Hotel dos Viajantes. Se eu não tiver enganada é um dos que vem primeiro assim, com o nome de hotel. Primeiro porque não usava essa terminologia, era pensão; qualquer lugar que você ia era pensão. Quando surgiu essa nova terminologia, passou de pensão para hotel [...]. Eles passaram a ficar concentrados aqui nessa parte mais alta, na parte central da cidade. Se você pegar de 2000 pra cá, aumentaram esses outros hotéis. O Hotel dos Viajantes eu acredito que foi o primeiro aqui a receber essa terminologia (DEPOIMENTO INFORMAL OBTIDO EM PESQUISA DE CAMPO, 2016-2018).

Conforme o antigo proprietário de uma pensão da cidade, o nome "hotel" surge no âmbito urbano quirinopolino por volta da década de 1980. Já segundo as informações colhidas nos trabalhos de campo, a Pensão Guanabara prestou serviços até os anos 1970, e a pensão Santa Isabel, até a década de 1980. Neste depoimento, é possível compreender a localização dos meios de hospedagens e destacar que a pensão:

Santa Isabel ficava nos fundos da CEQ, virada pra Rua Rio Preto. Ainda é uma pensão onde fica muito peão de usina. Passou a ser ponto de encontro [...], mas era [sic] as duas pensões de Quirinópolis, a de ponta era a Guanabara, e depois vinha a Santa Isabel, mas a primeira era da Dona Crioula, e de hotel era o Hotel dos Viajantes, e depois foi o Turis Hotel. Concentrava na Praça da Igreja Matriz, que era igual a essa pensão que tinha de frente ao Hospital São Francisco, ou na Rua Rio Preto, que era a Pensão Guanabara e a Santa Isabel. Há a Pensão da Dona Sabina onde é a Pizzaria Chalé, atual área central, ficava ali porque a cidade ia até a Rua Paranaiguara, onde é a Francisco Correia Neves ou a Rua Itumbiara. Da Rua Itumbiara pra baixo, Capelinha, Herculano Costa, José Joaquim Cabral e a Rua Baliza, que hoje é a Jose Salomão Lemes da Silva. As pensões no início dos anos 1950, 1960 ficavam concentradas na Rua Baliza, hoje José Salomão Lemes da Silva, e na Rua Rio Preto. A Pensão da Dona Crioula, na Avenida Brasil, e a pensão em frente ao hospital na Garibaldi Teixeira (DEPOIMENTO INFORMAL OBTIDO EM PESQUISA DE CAMPO, 2016-2018).

Em outros depoimentos de campo, foi relatado que as primeiras pensões surgiram em Quirinópolis em meados de 1948. No início, o primeiro hotel era uma pensão, mas somente 
EM

QUESTÃO

V.13 N. $03 \bullet 2020$

pág. 84-97

na década de 1980 que passou a ser chamado de hotel (Hotel dos Viajantes). De acordo com um dos entrevistados:

[...] o crescimento ocorrido no setor hoteleiro se deu com a expansão da cidade e juntamente com o êxodo rural. Em sequência surgiram alguns hotéis que atualmente não existe [sic] mais [...]. Por exemplo, há o hotel com o nome de Hotel Globo, que se localizava próximo ao Hospital Quirinópolis (DEPOIMENTO INFORMAL OBTIDO EM PESQUISA DE CAMPO, 2016-2018).

De acordo com Nacife (2012, p. 214), os maiores impulsionadores do setor hoteleiro de Quirinópolis são o comércio, a agricultura e a pecuária, por se referirem a atividades econômicas responsáveis por atrair pessoas. Para o referido autor, "[...] a pavimentação asfáltica das rodovias na década de [19]60 contribuiu fortemente, além de influenciar o crescimento da cidade".

Em sua tese, Santos (2010, p. 184) aborda os meios de hospedagem da região onde se localiza a cidade de Quirinópolis:

Os meios de hospedagens encontrados em todos os municípios do Baixo Paranaíba Goiano são hotéis, motéis, pousadas, pensões e áreas de camping, estabelecimentos simples e com gestão de base familiar, com exceção de alguns empreendimentos hoteleiros localizados nas cidades de São Simão e Lagoa Santa. [...] Nos lugares da microrregião quirinopolina, a maior parte dos meios de hospedagens e setores de alimentação tem seus gerenciamentos e serviços prestados, pautados nos laços de consanguinidade (SANTOS, 2010, p. 184).

Os meios de hospedagens comerciais e familiares são também responsáveis pela dinâmica de negócios das cidades pequenas espalhadas pelo interior de Goiás, com a geração de renda e a manutenção de um grupo gestor que investe minimamente nessas atividades, mas que cria um cenário responsável por atender um fluxo de sujeitos que buscam alternativas de hospedagens definidas nesses espaços urbanos como pensões.

Nos quintais das pensões do interior goiano, o:

Cultivo de hortaliças ainda é uma das principais características dos pequenos estabelecimentos hoteleiros instalados principalmente na cidade de Lagoa Santa. No relato de alguns gestores, foi afirmado que ainda cultivam, no entorno do hotel, por gostarem e com o intuito de continuar atendendo a antigos clientes que já estão acostumados a consumir os alimentos produzidos no lugar, mantendo assim aspectos de ruralidade nos serviços prestados (SANTOS, 2010, p. 185).

Santos (2010, p. 184) aduz que nas cidades pequenas da microrregião de Quirinópolis ainda existem hotéis, pensões e pousadas que funcionam em antigas residências e, com o aumento da demanda, "[...] os proprietários (moradores locais) foram transformando essas estruturas em espaços de locação, com quartos simples, banheiros privativos externos, sem telefone e televisão". Tal realidade está sendo transformada na região, pois os capitais investidos proporcionam novas estruturas de hospedagens, algo observado nas atividades de campo realizadas em 2016, 2017 e no início de 2018.

De acordo com Andrade, Brito e Jorge (1999, p. 21), "os proprietários da maioria das casas de pensão e hospedarias passaram a utilizar a denominação de hotel, com a intenção de 
EM

QUESTÃO

V.13 N. $03 \bullet 2020$

pág. 84-97

elevar o conceito de casa”. Esse caso ocorreu também na cidade de Quirinópolis: como foi observado na introdução deste artigo, a chegada das grandes usinas de açúcar e álcool dinamizou a economia local, assim como do setor hoteleiro.

Para Nacife (2012), existia na cidade a ideia de que a chegada das usinas iria favorecer a expansão de diversos segmentos de serviços na cidade, em especial do setor hoteleiro. Desse modo, ocorreu um investimento maior nas empresas de hospedagens, principalmente com a construção de novos hotéis e a ampliação dos mais antigos, mas sem qualificar gestores e mão de obra contratada.

Dessa maneira, o segmento hoteleiro recebe investimentos para atender a um determinado tipo de:

[...] visitantes (representantes comerciais, consultores e prestação de serviço para usinas). As características da cidade praticamente toda voltada para o comércio e agronegócio, onde não há outros fatores que impulsionam o setor [...] tal como a vinda das Usinas Sucroenergéticas para o município. [...] ficando o turismo de lazer influenciando o setor apenas quando se tem alguns atrativos como carnaval e festas tradicionais da cidade com o Rodeio Show, por exemplo. Ainda assim não sendo eventos que fundamentem a atração de investidores para o ramo hoteleiro, já que a demanda é apenas em alguns dias do ano, diferentemente do turismo de negócio onde a procura é o ano todo e a sazonalidade é pouca em relação ao turismo local (NACIFE, 2012, p. 215).

Com a chegada das usinas no início do século XXI, os negócios hoteleiros em Quirinópolis cresceram significativamente. Isso levou a ampliações e novas construções, "melhorando o município economicamente e gerando empregos a população, visto que a hotelaria cresce quando se tem alguns atrativos, que no caso da cidade referida são termos econômicos" (NACIFE, 2012, p. 216).

Quando se analisa a área da hotelaria em Quirinópolis, constata-se que ela abrange atividades de várias naturezas - prestação de serviços, qualidade de hospedagem, atendimento, alimentação, infraestrutura geral e de eventos -, em que a principal função é proporcionar satisfação aos seus clientes. Pode-se afirmar que o Hotel Rotas é a melhor opção de hospedagem da cidade, como pode ser verificado no depoimento de um dos gestores responsáveis pelo estabelecimento:

O nosso hotel se instalou em Quirinópolis na primeira década do século XXI, atraído principalmente pelo chamado desenvolvimento do agronegócio canavieiro. O hotel oferece café da manhã, 57 apartamentos de diferentes classificações (Master/Luxo/Executivo), centro de convenções, elevadores, estacionamento coberto, lavanderia, internet gratuita em todos os apartamentos, linha telefônica, televisão, ar-condicionado, mesa de trabalho com conexão à internet. Os melhores apartamentos possuem banheira com hidromassagem. Somos o único meio de hospedagem da cidade que oferece esses serviços; posso afirmar que nenhum outro hotel de Quirinópolis possui elevadores, isso para citar apenas um exemplo (DEPOIMENTO INFORMAL OBTIDO EM PESQUISA DE CAMPO, 2016-2018).

A partir desse excerto, afirma-se que a primeira década do século XXI foi marcada pela expansão e por pequenos processos de modernização dos serviços hoteleiros na cidade de Quirinópolis. O agronegócio contribui de forma absoluta e fundante para que a atividade se 
EM

tornasse responsável pela geração de emprego e renda, mesmo em um município que não possui aeroporto e onde os principais acessos ocorrem por rodovias estaduais.

Durante a pesquisa de campo, um questionário com perguntas objetivas foi aplicado a oito proprietários de estabelecimentos de hospedagens (hotéis e pensões) da cidade de Quirinópolis - tal instrumento de coleta de dados foi imprescindível para conhecer e analisar a atual realidade dos hotéis desse espaço urbano goiano. A maioria dos entrevistados $(55,56 \%)$ são homens, ao passo que o restante $(44,44 \%)$ é do sexo feminino.

Durante os trabalhos de campo foi notado que os hotéis pesquisados ainda buscam valorizar o trabalho familiar. Não existem profissionais preocupados com a formação profissional e pessoal na área, mas sim com os laços parentais, em detrimento de competências, habilidades e conhecimentos relacionados à hotelaria. Apenas 22,22\% dos inquiridos têm curso superior, mas nenhum em hotelaria ou turismo - outros $22,22 \%$ possuem apenas o ensino médio, e 44,44\% estão cursando graduação.

No cenário investigado, $100 \%$ das empresas disponibilizam duas opções de pagamento (dinheiro e cartão de crédito). Segundo um dos gestores, “[...] o cartão de crédito é uma ferramenta necessária para facilitar a vida do cliente, pois há um mercado que está em constante mutação e exige de nós, proprietários, uma modernização constante da empresa" (DEPOIMENTO INFORMAL OBTIDO DURANTE A APLICAÇÃO DOS QUESTIONÁRIOS, 2016-2018). Vale ressaltar que na maioria dos estabelecimentos pesquisados $(88,89 \%)$ é oferecido o café da manhã.

Em relação aos equipamentos e serviços disponibilizados pelos hotéis, identificou-se que $66,67 \%$ oferecem internet sem fio, $77,78 \%$ das Unidades Habitacionais (UHs) possuem telefones; $88,89 \%$, TVs; e 66,67\%, geladeiras - tais índices são justificados pela falta de percepção do potencial do mercado como forma de atrair novos clientes. Um universo de $88,89 \%$ dos proprietários investe na divulgação em mídias, especialmente em emissoras de rádio e internet.

Para $88,89 \%$ dos sujeitos pesquisados, os grandes responsáveis pela ocupação dos leitos hoteleiros são as empresas do agronegócio. O campo de atuação da hotelaria quirinopolina recebe organizações com essa e outras características, pois 33,33\% dos investigados atendem também visitantes que chegam para os eventos da Universidade Estadual de Goiás (UEG) e 44,44\% prestam serviços para a prefeitura da cidade. No total, os oito hotéis têm 222 UHs e empregam 96 funcionários que desenvolvem diferentes tarefas, mas não são profissionais especializados, com formação na área.

O cliente ainda encontra um atendimento (e relações) de base familiar. Diante dos resultados apresentados, torna-se necessário investir em qualificação profissional, mas sem perder os conteúdos de base familiar do negócio, vistos como uma particularidade do lugar.

Resultados de campo mostraram que os meios de hospedagem pesquisados têm uma taxa média de ocupação da ordem de 53\% a.a. (ao ano), comprovando uma grande movimentação de sujeitos na cidade. Na chegada das usinas produtoras de açúcar e álcool, ao final da primeira década do século XXI, a taxa média de ocupação chegou quase a $90 \%$ a.a., conforme informações dos entrevistados. No entanto, eles não souberam elencar os motivos econômicos que levaram a uma queda nos índices até 2018.

\section{Considerações finais}

Pode-se afirmar que as empresas hoteleiras de Quirinópolis (GO) se enquadram na categoria simples, mas também atendem um público que vai ao local com vistas a realizar atividades relacionadas à agropecuária, ao serviço público e ao ensino superior. Tais hotéis 
EM

possuem alta rotatividade devido ao seu baixo preço, e a qualidade dos serviços prestados não é adequada aos padrões encontrados em outras cidades. Vale ressaltar que, para 2019, não há a perspectiva de construção de novos empreendimentos inseridos na categoria Hotel.

A cidade possui eventos considerados importantes e conhecidos regionalmente, como o Carnaval, a Exposição Agropecuária, o Festival Gastronômico da Chica Doida e a Festa da Padroeira de Nossa Senhora da Abadia. Apesar de a atividade turística se manifestar nessas ocasiões, pelo fato de alguns visitantes procurarem os hotéis, a maioria ainda se hospeda em casas de parentes e amigos.

Por fim, pode-se dizer que, em se tratando do serviço hoteleiro, é necessária uma análise da demanda encontrada na cidade de Quirinópolis, com base em pesquisas de mercado. De fato, tal instrumento é eficiente no planejamento estratégico de qualquer empreendimento.

\section{Referências}

ALVES, B. M.; SILVA, L. G. O agronegócio e as transformações socioespaciais no município de Quirinópolis/Goiás, Brasil. Élisée, Rev. Geo. UEG - Porangatu, v.6, n.2, p.203-216, jul./dez. 2017.

AMAZONAS, E. Hotelaria: uma indústria em crescimento. 2006. Disponível em: <http://www.abih.com.br/site.php>. Acesso em: 27 jul. 2018.

ANDRADE, N.; BRITO, P. L.; JORGE, W. E. Hotel: planejamento e projeto. 6. ed. São Paulo: Senac, 1999.

BENI, M. C. Análise estrutural do turismo. São Paulo: Senac, 2003.

COSTA, J. de A.; SILVA, L. G. da. Migração, trabalho e escola: a inserção dos alunos nordestinos no Colégio Estadual Independência no município de Quirinópolis em 2015. Revista Mirante, Anápolis, v. 8, n. 2, p. 11-22, 2015.

CUNHA, L. Introdução ao turismo. Lisboa: Editorial Verbo, 2001.

CUNHA, L. Turismo em Portugal: sucessos e insucessos. Lisboa: Soares; Edições Universitárias Lusófonas, 2012.

FERREIRA, E. M.; FARANI, É.; SANTOS, J. C. V. Análise da oferta hoteleira e o perfil da demanda por serviços de hotelaria na cidade de Ituiutaba (MG). In: SIMPÓSIO DE GEOGRAFIA VALE DO PARANAÍBA/SIMGEO: REPENSANDO O ENSINO DE GEOGRAFIA: TENDÊNCIAS E PERSPECTIVA, 7., 2008, Quirinópolis. Anais... Quirinópolis: Piloto, 2008.

NACIFE, J. M. Setor hoteleiro em Quirinópolis: a extensão com o advento das empresas sucroenergéticas. In: URZEDO, M. da F. (Org.). Quirinópolis: mãos e olhares diferentes II (1936-2012). Goiânia: Kelps, 2012, p. 213-220.

RODRIGUES, S. Hotelaria no mundo. 2006. Disponível em: <http://www.pantanalms.tur.br/hotelaria2b.htm>. Acesso em: 26 set. 2018. 
EM

SANTOS, J. C. V. Políticas de regionalização e criação de destinos turísticos entre o Lago de São Simão e a Lagoa Santa no Baixo Paranaíba Goiano. 2010. 367 f. Tese (Doutorado em Geografia) - Universidade Federal de Uberlândia, Uberlândia, 2010.

SANTOS, J. C. V.; SILVA, J. A. A arte da olaria no turismo da região Algarve, Portugal. Turismo: Visão e Ação, Itajaí, v. 17, p. 658-690, 2015.

SOUZA, E. A. Patrimônio imaterial: relações socioculturais camponesas em Pedra Lisa. Uberlândia: Composer, 2015.

SOUZA, S. A. de; THOMAZ, R. C. C. Possibilidade para o turismo cultural: o caso da festa de São Sebastião no distrito de gardênia, município de Rancharia/SP. Élisée, v. 3, n. 2, p. 151161, jul./dez. 2014.

WALKER, J. R. Introdução à hospitalidade. 1. ed. Barueri: Manole, 2002.

Artigo recebido em 20-07-2019

Artigo aceito para publicação em 16-08-2020 